\title{
Opportunistic records of jungle cat (Felis chaus) and their activity pattern in Koshi Tappu Wildlife Reserve, Nepal
}

\author{
Rama Mishra $^{1,2,3 *}$ (i) | Birendra Gautam ${ }^{3}$ (D) | Shyam Kumar Shah ${ }^{4}$ (i) | Naresh Subedi ${ }^{3}$ iD $\mid$ Chiranjibi Prasad Pokheral ${ }^{3}$ (D) | \\ Babu Ram Lamichhane ${ }^{3}$ iD \\ 1 Department of Biology, Evolutionary Ecology Group, University of Antwerp, Belgium \\ ${ }^{2}$ Wildlife Conservation Association Nepal (WildCAN), Babarmahal, Kathmandu, Nepal \\ ${ }^{3}$ National Trust for Nature Conservation, POB 3712, Khumaltar, Lalitpur, Nepal \\ ${ }^{4}$ Department of National Parks and Wildlife Conservation, Babarmahal, Kathmandu, Nepal \\ *Correspondence: I.mishrarama@gmail.com
}

Received: 30 September 2019 | Revised: 24 March 2020 | Accepted: 06 June 2020

\begin{abstract}
Jungle cat (Felis chaus) is one of the widely distributed but less studied species in Nepal. We studied jungle cat distribution and their activity pattern in Koshi Tappu Wildlife Reserve (KTWR), Nepal. Photographs of the jungle cats obtained during camera trapping survey targeted to fishing cats in the winter season of two consecutive years (2016 and 2017) were used for this study. With an effort of 525 trap days from 69 stations, we obtained a total of 234 images/videos of jungle cats on 37 occasions from 15 stations. We recorded jungle cats distributed in the eastern buffer zone of the KTWR. All the jungle cat photographs were obtained in the night with peak activity within a couple of hours following the sunset. We suggest to carry out focused study specific to jungle cats to understand their distribution, status and diet.
\end{abstract}

Keywords: Buffer zone, Camera trapping, Koshi Tappu Wildlife Reserve, Small carnivore, Temporal activity pattern

\section{1 | Introduction}

Jungle cat (Felis chaus) ('Ban Biralo' in Nepali) is a close relative of the domestic cat (Felis catus) (Kitchener et al. 2016). Despite globally decreasing population, the jungle cat is listed as least concern in the IUCN Red List, globally (Gray et al. 2016), and in Nepal, nationally (Jnawali et al. 2011). Its global distribution is in North Africa (only Egypt), eastern Europe, south and southeast Asian countries with an elevational record of up to $4,000 \mathrm{~m}$ above sea level ( Nowell \& Jackson 1996, Jnawali et al. 2011). Despite the wide global distribution, their existence in selective habitats around the deciduous forest, riparian vegetation and permanent water sources results in their irregular distribution (Gray et al. 2014). Studies also show their adaptation in various types of agricultural lands where rodents are abundant (Ogurlu et al. 2010). Rodents contribute as a major diet of the jungle cat although they also consume hares, deer fawn, primates, reptiles and birds (Majumder et al. 2011). Jungle cats are ambush hunters and primarily active in the night (Majumder et al. 2011, Mukherjee et al. 2014). Activity pattern of carnivores is largely driven by the activity of prey species and interactions with other carnivores (Lynam et al. 2013).

In Nepal, jungle cats are recorded in a wide range from low land to up to $4,000 \mathrm{~m}$ altitudes (Jnawali et al. 2011). Due to the lack of species targeted research, their actual distribution in Nepal is unknown. This study presents the opportunistic records and temporal activity pattern of the jungle cat based on camera trap survey in Koshi Tappu Wildlife Reserve (KTWR) and its Buffer Zone (BZ) at the eastern lowland Terai of Nepal.

\section{2 | Materials and methods}

\section{1 | Study area}

This study was carried out in Koshi Tappu Wildlife Reserve (KTWR, location: $86^{\circ} 55^{\prime}-87^{\circ} 05^{\prime} \mathrm{E}$ and $26^{\circ} 34^{\prime}-26^{\circ} 45^{\prime} \mathrm{N}$ ) and its buffer zone (BZ) (Fig. 1). The KTWR was established in 1976, 
covering an area of $175 \mathrm{~km}^{2}$ in the southeast part of Nepal. The reserve is the first Ramsar site of Nepal, listed in 1987. Additional $173 \mathrm{~km}^{2}$ area surrounding the reserve was declared as BZ in 2004. The reserve is the habitat of many globally threatened mammals like wild water buffalo (Bubalus arnee), gangetic dolphin (Platanista gangetica), fishing cat (Prionailurus viverrinus), smooth coated otter (Lutrogale perspicillata); reptiles like gharial (Gavialis gangeticus); and endangered birds such as swamp francolin (Francolinus gularis) and Bengal florican (Houbaropsis bengalensis) (Chettri et al. 2013).

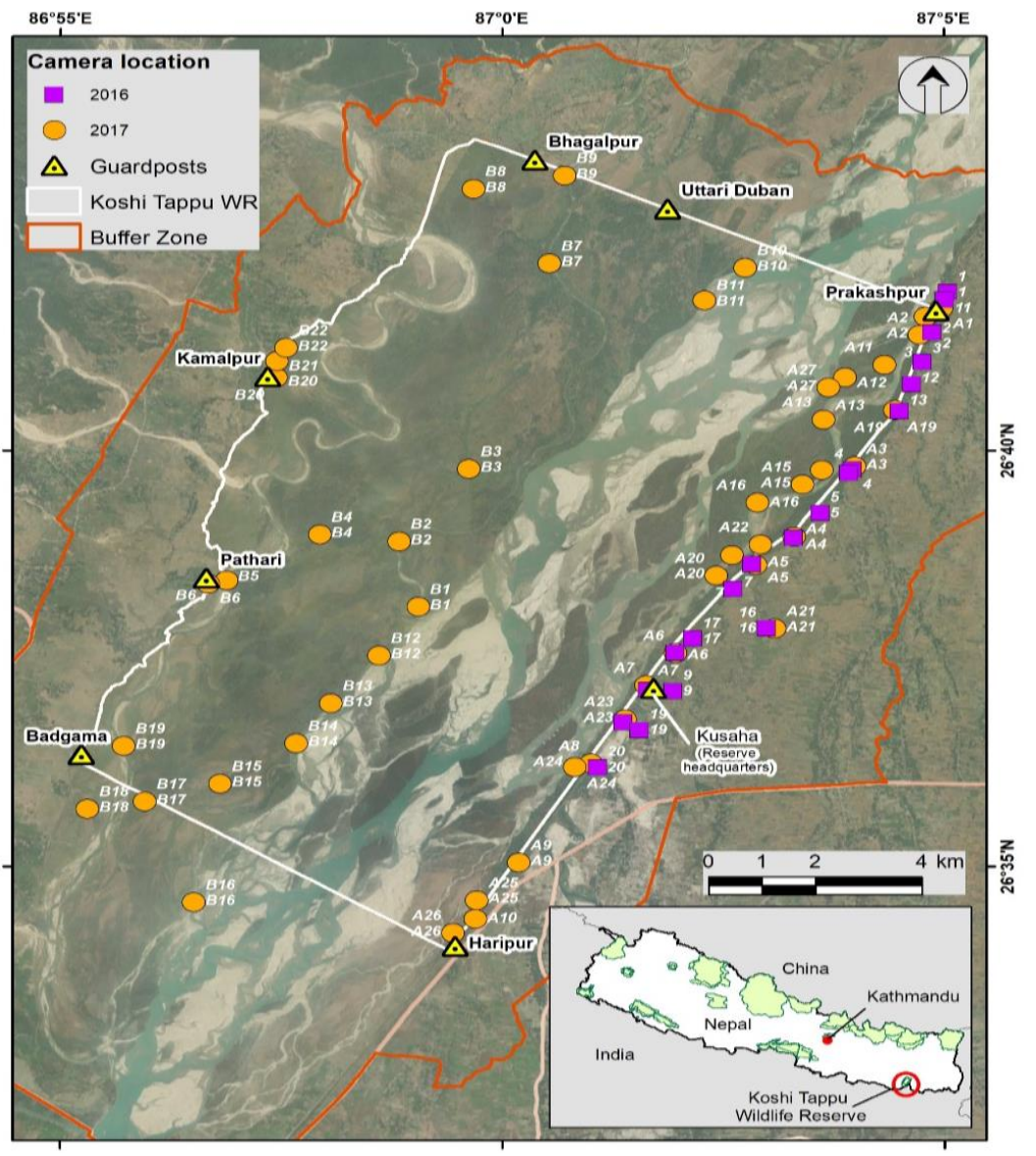

Figure 1. Map of Koshi Tappu Wildlife Reserve showing the camera trap locations.

The KTWR entirely lies in the floodplain of the Koshi River. Majority of the reserve is covered by grasslands followed by sand/gravel, water bodies and forests. It is one of the important protected areas with a freshwater ecosystem of the snow-fed Koshi River. However, the KTWR is facing rapid land cover change, especially wetlands (decreased by $>30$ since its establishment), which has a critical impact on habitat specialized species (Chaudhary et al. 2016, Taylor et al. 2016). Along with jungle cat, the reserve holds other carnivores such as fishing cat, golden jackal (Canis aureus), Bengal fox (Vulpes bengalensis), small Indian civet (Viverricula indica) and mongoose (Herpestes spp.). The herbivore species include nilgai (Boselaphus tragocamelus), hog deer (Axis porcinus), chital (Axis axis), barking deer (Muntiacus vaginalis), rhesus macaque (Macaca mulatta) and Indian hare (Lepus nigricollis). At the eastern BZ of the KTWR, the seepage of water from the Koshi River embankment formed continuous wetlands. Gradually these wetlands have been converted into the private fish ponds. Some ponds are abandoned and provide natural habitats for small native fish, amphibians, crustaceans and molluscs. These species can contribute as a worthy source of diet to small carnivores including jungle cats surviving there.

\section{2 | Camera trap methods}

We conducted a camera trap survey during the cold-dry season (November and December) of two consecutive years in 2016 and 2017. The survey was primarily designed to study the fishing cat which may have caused the placement bias for optimum photo-capture of the jungle cat. We set digital motion sensor cameras (Reconyx Hyperfire HC550, Bushnell Trophy Cam HD and Cuddeback E) (Fig. 1) in the field for a minimum of seven days operating 24 hours a day. The survey of the first year (2016) focused on the private fish farms in its eastern BZ. Intensive camera trapping was carried out in the fish farms ( $n=20$ ) with spatial coverage (ca. $500 m$ apart). Camera traps were set to cover all possible routes of predators into the pond (Fig. 1).

In the second year (2017), camera traps were placed in both private fish farm in the BZ area ( $=22)$ and core area of the reserve $(n=27)$. Inside the reserve, camera traps were set up consistently around the wetlands in order to photograph the animals approaching close to the vicinity of water. A pair of camera traps were placed at a location facing opposite to each other for taking the photographs of both side of animals (Fig. 1). In both surveys, camera traps were programmed to take three photos per trigger followed by 10 seconds of video. GPS coordinates were recorded during the camera installation with the help of Garmin eTrex 10. All the images obtained from the camera traps were downloaded, renamed and sorted species wise in different folders. 


\section{3 | Distribution of jungle cat}

The locations of camera traps where the jungle cats were photographed were used to develop their distribution map in KTWR. ArcGIS 10.4 was used to prepare the distribution map (ESRI 2015).

\section{4 | Activity pattern of jungle cat}

Date and time of the jungle cat images/videos were entered into the Excel spreadsheet. Temporal activity pattern was calculated using a non-parametric kernel density function (Ridout \& Linkie 2009) of activity detected by camera-traps. The analysis was conducted using the 'overlap' package in R Program (R Core Team 2017).

\section{3 | Results}

\section{1 | Distribution of jungle cat}

With the effort of 525 camera trap days, from 69 locations, we obtained altogether 224 images and seven video clips of jungle cats. Jungle cats were photographed on 37 occasions from 15 locations (Fig. 2) with a detection rate of 7.04 detections per 100 trap days. Jungle cat photographs were obtained from the eastern $B Z$ only with no detection inside the reserve. The jungle cat was photographed once only from seven locations whereas from a location it was photographed up to 12 times (Table 1). From the location with 12 detections (ID 5, 2016), we also detected the jungle cat carrying a snake on an occasion, probably as a prey (Fig. 3).

\subsection{Activity pattern}

All the jungle cat photographs were recorded in the night with a peak at the dusk (18:00-19:00 hours). No jungle cat photographs were detected in between 06:00 to 17:00 hours (Fig. 4).

Table 1. Jungle cat detection events in camera trap locations.

\begin{tabular}{|c|c|c|c|c|}
\hline \multirow{2}{*}{ Year } & \multicolumn{3}{|c|}{ Camera stations where Jungle Cat was Captured } \\
\hline $\mathbf{2 0 1 7}$ & Once & Twice & Thrice & 12 times \\
\hline $\mathbf{2 0 1 7}$ & ID A18 & & & \\
\hline $\mathbf{2 0 1 7}$ & ID A19 & & & \\
\hline $\mathbf{2 0 1 6}$ & ID A21 & & & \\
\hline $\mathbf{2 0 1 6}$ & ID 03 & ID 02 & ID 01 & ID 05 \\
\hline $\mathbf{2 0 1 6}$ & ID 14 & ID 13 & ID 11 & \\
\hline $\mathbf{2 0 1 6}$ & ID 18 & ID 16 & ID 12 & \\
\hline
\end{tabular}

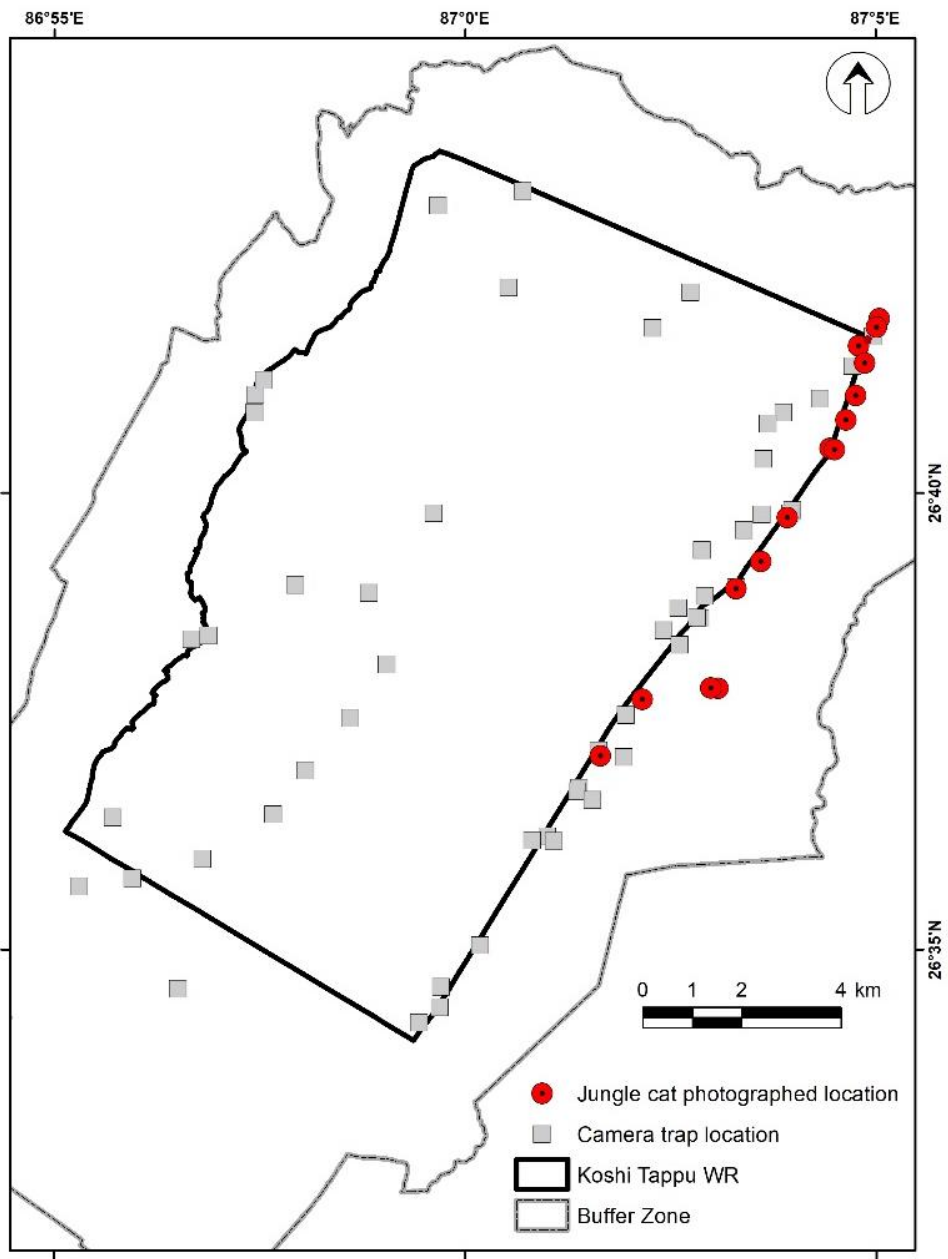

Figure 2. Distribution of jungle cat based on camera trap detections in Koshi Tappu Wildlife Reserve and its buffer zone.

\section{4 | Discussion}

Our study in the KTWR documented the jungle cat distribution in the eastern $\mathrm{BZ}$ with no detection from the core area of the reserve and its western BZ. Our study design was targeted to fishing cats which might have affected for the optimum detection of the jungle cat. In the eastern $\mathrm{BZ}$, there are numerous commercial fish ponds close to the reserve boundary. Although jungle cats are not dependent directly on the wetlands, they may prefer to live close to wetlands as described by Abu Baker et al. (2003) in Jordan. In India, jungle cat has no strong connection with close dense forest but is related with the closeness of water like near lakes, along the riverside (Ogurlu et al. 2010). But in our study jungle cats were not recorded from natural lakes or along the riverside. They were recorded only from permanent wetlands with fish farming sites along with agricultural land. In the region, thick bushes along the dike of the Koshi River in the eastern part of KTWR close to 

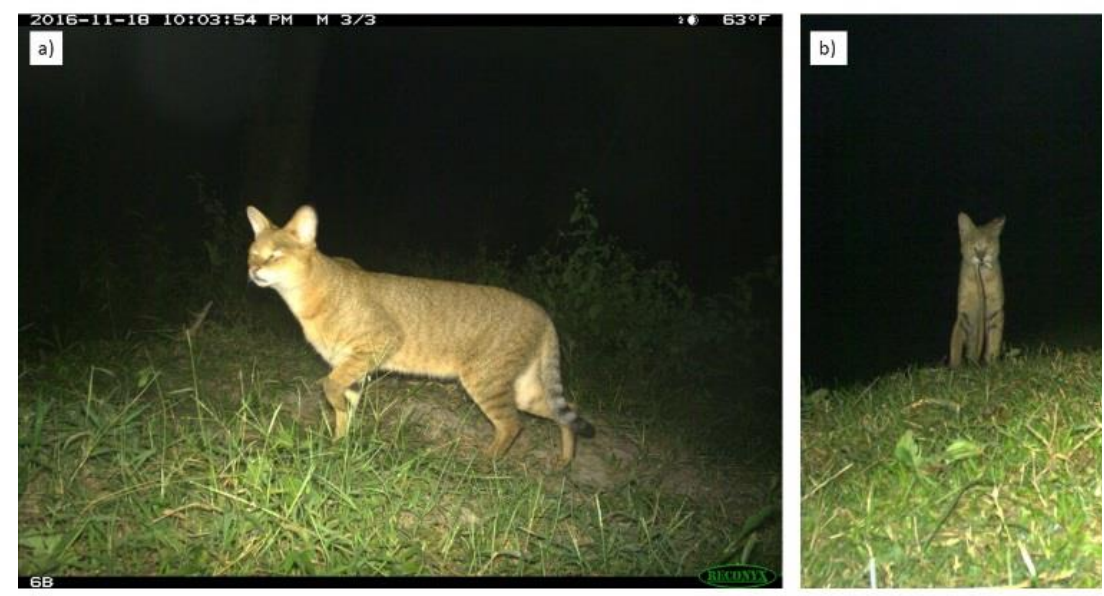

Figure 3. Jungle cat camera trapped in eastern buffer zone of Koshi Tappu Wildlife Reserve (a), and jungle cat carrying a snake at the edge of a fish pond (b).

the fish farm may offer a refuge for this cat at day time. There are agricultural fields beside the fish farms where paddy was growing and almost ready to harvest during our surveys. The availability of rodents in the agricultural areas during this paddy season may have attracted jungle cats. It seems jungle cats move to the fish farm and agricultural land nearby at night time for foraging. This may explain the reason for peak movement just after dark. In the western BZ, agriculture pattern is similar but are without fish ponds.

Our study documented all the records of jungle cats in the dark. Similar records are presented by other studies in India (Majumder et al. 2011) and Turkey (Ogurlu et al. 2010); except contrasting finding from Cambodia (Gray et al. 2014) with activity during daylight. The daylight time during our survey (November to December) in the survey site was between 06:15-17:10. All the camera trapping occasions $(n=37)$ of the jungle cat lies beyond

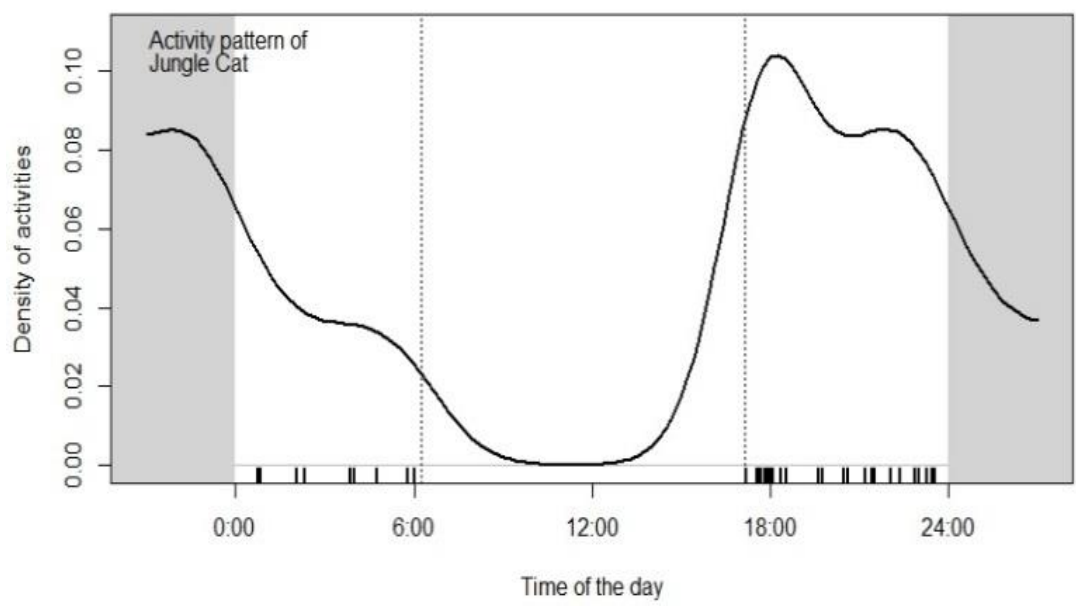

Figure 4. Temporal activity of jungle cat in Koshi Tappu Wildlife Reserve. Dotted vertical lines represent the sunrise and sunset time during the survey period. Each vertical line at the bottom represents a detection of jungle cat in camera trap. this time frame. Jungle cats are found moving towards the side of the ponds following the sunset. But our study cannot prove either jungle cats involved in searching rodents and other prey around the fish pond or they also take fish from the ponds. However, we also documented an incident of jungle cat carrying snake probably as prey. Jungle cats are reported to consume a wide variety of diet including snakes and other herpetofauna (Mukherjee et al. 2004, Majumder et al. 2011). The abundance of such herpetofauna near the ponds may have lured the jungle cats towards the fish ponds. Cameras were installed in fish farms close to villages which are disturbed by human activities during the day which may have caused the jungle cats to shift their activity in the night.

Differentiating jungle cat individuals using camera trap photos is difficult. Thus, we only presented the number of detections and detection rate of jungle cats and we don't have the idea about their population. Apart from the population, diet and conservation threats are also not understood in our study area. Informal interactions of the first author during the survey with the local people in KTWR found that farmers consider jungle cats as a pest of their poultry. Such attitude of local people could be a threat for the survival of jungle cats which are living in the fringes of communities. Fishing cats, the other predators of similar size specializing on fishing, also visit frequently in these fish farms (Taylor et al. 2016). Interaction between them is also not well understood. Also, it is believed that the distribution of the jungle cat has been affected by the degraded natural wetlands in the study area.

\section{5 | Conclusions}

This study shows jungle cat distribution in the eastern buffer zone of KTWR and their nocturnal activity. However, its occurrence inside the reserve is not well understood. Targeted study on jungle cat distribution, habitat and diet in KTWR is needed for their conservation. Moreover, understanding the variation in their distribution with respect to the seasons is also important. 


\section{Acknowledgements}

We thank National Trust for Nature Conservation (NTNC) and KTWR for their support in this study. We like to acknowledge Taronga Foundation for providing the grants for fishing cat research. We like to thank Department of National Parks and Wildlife Conservation for permitting to conduct this survey. We acknowledge the contribution of $\mathrm{Dr}$ lain R. Taylor for initiating and fundraising for the project and Dr. Jim Sanderson for his support in species identification of photographs. We would like to thank Ms. Prativa Kaspal and the technicians of NTNC Mr. Purna Lama, Mr. Deep Prasad Chaudhary and Mr. Ramesh Darai who helped in the field for camera trap survey. We also like to thank staffs of KTWR especially Mr. Binda Sardar, Mr. Dev Kumar Biswas, Mr. Arjun Karki and Ms. Bunu Rana. Finally, we like to thank the local communities including Mr. Bimal Mandal and Mr. Gulabi Mukhiya who allowed camera trap in their fish farm area and supported directly/indirectly during fieldwork

\section{Authors' contributions}

Mishra, R., Subedi, N. and Lamichhane, B. R. designed the research; Mishra, R. and Gautam, B. conducted the fieldwork. All authors wrote the manuscript. All authors contributed critically to the drafts and gave final approval for publication.

\section{Conflicts of interest}

Authors declare no conflict of interest.

\section{ORCID}

Rama Mishra (D) https://orcid.org/0000-0002-8648-7256

Birendra Gautam (D) https://orcid.org/0000-0001-7406-3416

Shyam Kumar Shah iD https://orcid.org/0000-0002-0893-6968

Naresh Subedi (D) https://orcid.org/0000-0003-4517-4912

Chiranjibi Prasad Pokheral (D) https://orcid.org/0000-0001-7252-1946

Babu Ram Lamichhane (D) https://orcid.org/0000-0003-0580-7682

\section{References}

Abu Baker, M., Nassar, K., Rifai, L., Qarqaz, M., Al-Melhim, W. and Amr, Z. 2003. On the current status and distribution of the jungle cat, Felis chaus, in Jordan (Mammalia: Carnivora). Zoology in the Middle East 30:5-10. https://doi.org/10.1080/09397140.2003.10637982

Chaudhary, S., Chettri, N., Uddin, K., Khatri, T. B., Dhakal, M., Bajracharya, B. and Ning, W. 2016. Implications of land cover change on ecosystems services and people's dependency: A case study from the Koshi Tappu Wildlife Reserve, Nepal. Ecological Complexity 28:200-211. https://doi.org/10.1016/j.ecocom.2016.04.002

Chettri, N., Uddin, K., Chaudhary, S. and Sharma, E. 2013. Linking spatio-temporal land cover change to biodiversity conservation in the Koshi Tappu Wildlife Reserve, Nepal. Diversity 5(2):335351. https://doi.org/10.3390/d5020335

ESRI (Environmental Systems Research Institute). 2015. ArcGIS Release 10.4. Redlands, CA: Esri Inc.

Gray, T. N. E., Timmins, R. J., Jathana, D., Duckworth, J. W., Baral, H. and Mukherjee, S. 2016. Felis chaus. The IUCN Red List of Threatened Species 2016: e.T8540A50651463. https://dx.doi.org/10.2305/-IUCN.UK.2016-2.RLTS.T8540A50651463.en

Gray, T. N. E., Phan, C., Chanrattanak, P. and Sovanna, P. 2014. The status of jungle cat and sympatric small cats in Cambodia's Eastern Plains. Cat News 8:19-23.

Jnawali, S. R., Baral, H. S., Lee, S., Acharya, K. P., Upadhyaya, G. P., Pandey, M. et al. 2011. The Status of Nepal's Mammals: The National Red List Series. Kathmandu, Nepal: Department of National Parks and wildlife Conservation. Retrieved from https://ntnc.org.np/publication/status-nepals-mammals-nationalred-list-series. Accessed on 16 June 2020.

Kitchener, A. C., Breitemoser-Würsten, Ch., Eizirik, E., Gentry, A., Werdelin, L., Wilting, A. et al. 2016. A revised taxonomy of the Felidae. The final report of the Cat Classification Task Force of the IUCN Cat Specialist Group. Cat News Special Issue 11, pp 80.

Lynam, A. J., Jenks, K. E., Tantipisanuh, N., Chutipong, W., Ngoprasert, D., Gale, G. A. et al. 2013. Terrestrial activity patterns of wild cats from camera-trapping. Raffles Bulletin of Zoology 61(1):407-415.

Majumder, A., Sankar, K., Qureshi, Q. and Basu, S. 2011. Food habits and temporal activity patterns of the golden jackal Canis aureus and the jungle cat Felis chaus in Pench Tiger Reserve, Madhya Pradesh. Journal of Threatened Taxa 3(11):2221-2225.

Mukherjee, S., Goyal, S. P., Johnsingh, A. J. T. and Pitman, M. L. 2004. The importance of rodents in the diet of jungle cat (Felis chaus), caracal (Caracal caracal) and golden jackal (Canis aureus) in Sariska Tiger Reserve, Rajasthan, India. Journal of Zoology 262(4):405-411.

Nowell, K. and Jackson, P. 1996. Wild cats. Status survey and conservation action plan. UCN, Gland, Switzerland. Retrieved from https://portals.iucn.org/library/node/6998. Accessed on 16 June 2020 
Ogurlu, I., Gundogdu, E. and Ceyhun Yildirim, I. 2010. Population status of jungle cat (Felis chaus) in Egirdir lake, Turkey. Journal of Environmental Biology 31:179-183.

R Core Team. 2017. R: A language and environment for statistical computing. R Foundation for Statistical Computing, Vienna, Austria. URL https://www.R-project.org/.

Ridout, M. S. and Linkie, M. 2009. Estimating overlap of daily activity patterns from camera trap data. Journal of Agricultural, Biological, and Environmental Statistics 14(3):322-337. https://doi.org/10.1198/-jabes.2009.08038

Taylor, I. R., Baral, H. S., Pandey, P. and Kaspal, P. 2016. The conservation status of the fishing cat Prionailurus viverrinus Bennett, 1833 (Carnivora: Felidae) In Koshi Tappu Wildlife Reserve, Nepal. Journal of Threatened Taxa 8(1):8323-8332. https://doi.org/10.11609/jott.-2034.8.1.8323-8332

\section{Cite this article as:}

Mishra, R., Gautam, B., Shah, S. K., Subedi, N., Pokheral, C. P., and Lamichhane, B. R. 2020. Opportunistic records of jungle cat (Felis chaus) and their activity pattern in Koshi Tappu Wildlife Reserve, Nepal. Nepalese Journal of Zoology 4(1):50-55. https://doi.org/10.3126/njz.v4i1.30673 